\title{
El diagnóstico participativo para la elaboración del plan de formación ciudadana"
}

\author{
Participatory diagnosis to elaborate the citizenship education plan \\ Patricia Ojeda Millahueque \& Carmen Gloria Zúñiga GonZÁlez $^{\mathrm{b}}$ \\ aPontificia Universidad Católica de Chile, Santiago, Chile. § piojeda@uc.cl \\ [orcid.org/0000-0001-8723-4827] \\ bPontificia Universidad Católica de Chile, Santiago, Chile. carmen.zuniga@uc.cl \\ [orcid.org/0000-0001-6031-9687]
}

\section{RESUMEN}

La elaboración de los Planes de Formación Ciudadana en escuelas chilenas se ha caracterizado por ser de naturaleza poco participativa (PNUD, 2018), lo que ha contribuido a que no posean un sentido formativo y se consideren meros requerimientos ministeriales. El objetivo de esta investigación es diseñar un Diagnóstico Participativo para la elaboración del Plan de Formación Ciudadana, promoviéndolo como una herramienta de reflexión en torno a los problemas y desafíos de la comunidad educativa y como un espacio de participación comunitaria. Se examinan los datos obtenidos del diseño de esta propuesta en una escuela particular subvencionada de la comuna de El Bosque, Santiago, a través de una Investigación Acción Participativa. Para ello, se analizaron cualitativamente los datos de entrevistas grupales e individuales. Los resultados caracterizan conocimientos, habilidades y actitudes ciudadanas de la comunidad escolar e identifican sus espacios de participación ciudadana dentro de la escuela.

PALABRAS CLAVE: Diagnóstico Participativo, Plan de Formación Ciudadana, Investigación Acción Participativa.

\section{ABSTRACT}

The elaboration of Citizenship Education Plans in Chilean schools has been characterized by not having a participatory nature (UNDP, 2018), which has contributed to their lack of

Financiado por CONICYT - PFCHA/Magíster PPEE Nacional/ 2017-folio SBBB0242017

Proyecto FONDECYT 11150165 Prácticas efectivas de profesores destacados y competentes en la enseñanza de la Historia, Geografía y Ciencias Sociales. 
formative meaning and being considered mere ministerial requirements. The objective of this research is to design a Participatory Diagnosis for the preparation of the Citizenship Education Plan, promoting it as a tool for reflection on the problems and challenges of the educational community and as a space for community participation. Following a participatory action research methodology, data was collected from a subsidized private school in the commune of El Bosque, Santiago. For this purpose, data from group and individual interviews were analyzed qualitatively. Results characterise knowledge, skills and citizen attitudes of the school community and identify their spaces for citizen participation within the school.

KEY WORDS: Participatory Diagnosis, Citizenship Education Plan, Participatory Action Research.

\section{LA FORMACIÓN CIUDADANA}

Los procesos de participación juvenil en el contexto nacional muestran diversas tendencias. Por una parte, ha disminuido la participación electoral juvenil de manera sistemática desde principios de la década de los '90, en especial luego de aprobado el voto voluntario (PNUD, 2017); por ejemplo, según datos del Servel, sólo un 35\% de los jóvenes de 18 y 19 años votaron en las elecciones presidenciales del 2017. Por otra parte, se ha manifestado una creciente participación en manifestaciones populares, en especial después de octubre del año 2019, por medio de protestas, marchas, asambleas territoriales y organizaciones barriales (Garcés, 2020). En ellas los estudiantes cobraron protagonismo al alentar la evasión del transporte público en la Región Metropolitana bajo la consigna "Evadir, no pagar, otra forma de luchar".

Esta no es una tendencia nueva, pues González (2007), hace más de 13 años señalaba que el menor interés de los jóvenes en participar en las elecciones se debe a la desconfianza y deslegitimación de la institucionalidad política y los procedimientos democráticos. Sin embargo, lo anterior no significa que exista desinterés por lo político o lo público. Ejemplo de ello, es que existe una destacable participación de los jóvenes en otras actividades destinadas al servicio a la comunidad. Nuestro país duplica el promedio internacional respecto a trabajos voluntarios, con un $45 \%$ contra un 22\%, respectivamente (Miranda, 2011). Incluso Reyes y otros autores (2013) relacionaban el alto interés político y las prácticas ciudadanas de los estudiantes con las movilizaciones sociales que han llevado a cabo los estudiantes en nuestro país, tales como el "Mochilazo" del año 2001, la "Revolución Pingüina" del año 2006, los liceos autogestionados del año 2008, las movilizaciones estudiantiles del 2011, entre otras, lo que ha estado aparejado a la fundación de Asambleas de Estudiantes Secundarios como la ACES y CONES. De esta manera, aunque la participación electoral de los jóvenes es baja, su compromiso cívico con la comunidad no se ha visto mermado (Martínez et al. 2010).

Desde la institucionalidad, el Ministerio de Educación ha elaborado diversas propuestas con el fin de fomentar la formación de ciudadanos en las escuelas. Desde la concepción de Educación 
Cívica que prevaleció en el siglo anterior, se dio paso a la Formación Ciudadana, que promueve el despliegue de competencias al incorporar conocimientos, habilidades y actitudes bajo el enfoque de educar para la ciudadanía (Mineduc, 2016a), que son abordados desde una perspectiva transversal a lo largo de toda la formación escolar en diferentes asignaturas (Miranda, 2011).

Los años 2009 y 2016 se aplicó en Chile el International Civic and Citizenship Education Study (ICCS) con el fin de investigar las maneras en que los jóvenes de Octavo Básico están preparados para asumir sus funciones como ciudadanos en el siglo XXI. Los resultados evidenciaron que el conocimiento cívico de los estudiantes en Chile está bajo la media internacional y se mantuvo estable desde 2009. Asimismo, Chile presenta cifras inferiores con respecto al promedio internacional en el nivel de confianza en el gobierno, parlamento y tribunales de justicia, la participación en actividades políticas fuera de la escuela y las expectativas de participación electoral futura (Agencia de Calidad de la Educación, 2017).

Dentro de los resultados positivos del ICCS 2016 podemos indicar que los estudiantes de Chile muestran una actitud favorable frente a la igualdad de género y la igualdad de derechos para todos los grupos étnicos. Además, el porcentaje de estudiantes que ha participado votando o presentándose como candidatos en las elecciones de la escuela está por sobre el promedio internacional, al igual que el porcentaje que participa en actividades de voluntariado fuera de la escuela (Agencia de Calidad de la Educación, 2017).

Los resultados del año 2016 también muestran que, controlado por variables relevantes, el nivel socioeconómico de los estudiantes y de la escuela, las expectativas de alcanzar la educación superior, ser mujer, pertenecer a una escuela con un clima abierto a la discusión en clases y en donde se enseñan temas cívicos, se relacionan positivamente con mejores resultados en conocimiento cívico (Agencia de Calidad de la Educación, 2017). Estos resultados explicitan la influencia que tienen los padres, apoderados, profesores y comunidad escolar en el conocimiento cívico de los estudiantes.

A su vez, el año 2018 se realizó el Primer Estudio Nacional de Formación Ciudadana en Octavo Básico. Entre los resultados se visibilizó que uno de cada tres estudiantes no cree que la democracia sea la mejor forma de gobierno. A ello se agrega la desigualdad de los resultados, ya que los estudiantes de grupo socioeconómico bajo y los estudiantes hombres presentan resultados más bajos (Agencia de Calidad de la Educación, 2018). Estos resultados demuestran el desafío que tienen las escuelas en mejorar la preparación de sus estudiantes para que puedan asumir su rol como ciudadanos.

\section{PARTICIPACIÓN CIUDADANA}

La participación de los estudiantes en el consejo de curso, las directivas y los centros de alumnos, así como la participación en organizaciones fuera de la escuela son instancias que actualmente se consideran un factor importante que mejora los aprendizajes en ciudadanía de los estudiantes (Agencia de Calidad de la Educación, 2018). 
El desarrollo de competencias ciudadanas está relacionado directamente con la creación de una cultura escolar democrática, la que implica una gestión horizontal, en donde los estudiantes tengan la posibilidad de compartir sus opiniones acerca de los problemas escolares y participar en actividades que los vinculen con la comunidad (Jara, Sánchez \& Cox, 2019). Esto se traduce en que tanto a nivel escuela como dentro de la sala de clases se planifiquen instancias de participación efectiva, donde los estudiantes puedan ejercerla, mediante la generación de consensos, la promoción del diálogo, de procesos de deliberación y de toma de decisiones de forma colectiva (Cabrera, Donoso, Folgueiras \& Luna, 2009).

De esta forma, estainvestigación concibe una noción multidimensional de la participación (Folgueiras, 2009) que se relaciona con diferentes niveles y grados de implicación. Respecto a los niveles, seguimos el modelo de Novella y Trilla (Novella, 2008) que distingue entre participación simple (estudiantes no se involucran en las decisiones), consultiva (estudiantes opinan sobre las decisiones), proyectiva (estudiantes forman parte de las decisiones) y metaparticipación (estudiantes exigen ampliar los espacios de participación). Por su parte, los grados de implicación se relacionan con los motivos que llevan a los estudiantes a participar, ya sea por ansias personales o las posibilidades reales de poder participar (espacios, temporalidad, elementos organizativos, etc.) con el fin de dotar de significación social su experiencia en la escuela.

\section{EL PLAN DE FORMACIÓN CIUDADANA}

La Ley N 20.911 del año 2016 mandata a todos los establecimientos educacionales a implementar un Plan de Formación Ciudadana (en adelante PFC). La ley tiene como objetivo principal preparar a los estudiantes para asumir una vida responsable en la sociedad y orientar "el mejoramiento integral de la persona humana como fundamento del sistema democrático, la justicia social y el progreso" (Ley 20.911, 2016).

El PFC debe visibilizar las acciones relacionadas con la formación ciudadana que se realizan en las escuelas y potenciar su promoción a través de la apertura de los centros a la comunidad, de actividades extraprogramáticas y el fomento de la participación democrática dentro del establecimiento. Para lograr esta propuesta se espera que las escuelas den cumplimiento a nueve objetivos que promueven una ciudadanía crítica, responsable, respetuosa, abierta y creativa (Ley 20.911, 2016).

Además, se busca que cada PFC responda y se ajuste a las características de cada comunidad educativa, otorgándole facilidades a las escuelas para que cada una lo desarrolle de manera autónoma y acorde con sus proyectos educativos. Para ello, el MINEDUC entregó una serie de herramientas y estrategias para su planificación e implementación y se publicaron en línea una serie de documentos para orientar la elaboración del PFC, entre ellos: Orientaciones para la elaboración del Plan de Formación Ciudadana (2016), Orientaciones curriculares para el desarrollo del Plan de Formación Ciudadana (2016) y Orientaciones para la participación 
de las comunidades educativas en el marco del Plan de Formación Ciudadana (2017). En estos documentos se plantean diversas sugerencias con el fin de alinear y promover actividades en la escuela para la creación e implementación de manera participativa de un PFC.

Es así como se genera una serie de medidas de descentralización cuyo objetivo es el diseño de acciones ajustadas a cada realidad educativa, siguiendo una lógica de autodiagnóstico (PNUD, 2018). Se busca que en el espacio escolar se potencie la democracia y los derechos humanos, utilizando estrategias de enseñanza adecuadas que incidan en el aula, la comunidad y en actividades extracurriculares.

\section{LA IMPLEMENTACIÓN DEL PLAN DE FORMACIÓN CIUDADANA}

Según la investigación realizada por el PNUD (2018), ha existido un bajo logro de implementación del PFC y ha prevalecido una lógica de elaboración, en donde un pequeño grupo o incluso sólo un profesional tiene la responsabilidad de elaborarlo, sin lograr un diseño participativo. Por lo general son los jefes de UTP, el encargado de Convivencia Escolar o el profesor de Historia quienes elaboran el Plan sin consultarle a la comunidad educativa, sosteniendo una visión solamente de difusión o aprobación del PFC por parte de los actores de la comunidad. Esto es un problema, ya que, al contar con un proceso de elaboración menos participativo, muchas veces este Plan pasa a convertirse en sólo un requerimiento ministerial, dejando esta política sin su sentido formativo. Las últimas investigaciones (Jara et al. 2019; Zúñiga, Ojeda, Neira, Cortés \& Morel, 2020) han demostrado que estas dificultades se han mantenido en el tiempo.

Los directivos no perciben el PFC como algo importante, ya que no ha implicado un cambio significativo con respecto a la formación ciudadana en las escuelas, sino que más bien, el Plan se ha convertido en un listado de actividades que se realizan en la escuela (Jara et al. 2019). Zúñiga y otros autores (2020) refuerzan esta idea indicando que no ha habido nuevas acciones creadas especialmente para el PFC, sino que, en su mayoría, son acciones que se realizaban antes de la promulgación de la Ley N ${ }^{\circ}$ 20.911. Aunque los participantes de estos estudios coinciden en que la Formación Ciudadana es relevante en la escuela, no se vislumbra al PFC como una herramienta que aporte a esta temática en las escuelas.

En consecuencia, uno de los desafíos que se presentan para esta ley es considerar a todos los estamentos de la escuela en la implementación del PFC: estudiantes, profesores, apoderados, directivos y asistentes y hacer un diseño más participativo. Esto debiera considerar tanto el proceso de elaboración, como también, avanzar hacia lograr una participación sistemática y no puntual en la implementación del Plan y en la evaluación de las acciones realizadas, con el fin de visibilizar y potenciar el PFC en las escuelas.

El PNUD (2018) sugiere desarrollar un trabajo más sistemático de elaboración con protocolos y tiempos garantizados para lograr una elaboración en conjunto con los distintos actores de la comunidad educativa. De esta manera se podría lograr un mayor compromiso en la realización efectiva de las actividades diseñadas. Además, según la Ley № 20.911 (2016) 
la escuela tiene el deber de proveer de espacios de participación a la comunidad, ya que constituye uno de los elementos esenciales para el desarrollo de la ciudadanía. En particular, se sugiere conocer los intereses de los estudiantes para planificar acciones significativas para ellos y promover la relación e involucramiento de los apoderados en el PFC (PNUD, 2018).

La formación ciudadana implica generar una democracia al interior de la escuela que es por definición una institución caracterizada por la jerarquía de autoridad y de conocimiento (Crescimbeni, 2015). El ejercicio de un liderazgo jerárquico en la escuela, donde los equipos directivos toman todas las decisiones, torna dificultoso la relación con el resto de la comunidad educativa, ya que no existe el hábito de escuchar opiniones de otros actores (PNUD, 2018).

Otras debilidades en la implementación del PFC, según el Informe PNUD (2018), son que sus iniciativas se encuentran desarticuladas con los demás planes del establecimiento, como por ejemplo el Plan de Gestión de la Convivencia Escolar, el Plan de Sexualidad, Afectividad y Género, el Plan de Apoyo a la Inclusión y el Plan Integral de Seguridad Escolar, lo que deriva en la realización de acciones en paralelo para abordar los distintos planes. Incluso el PFC no siempre se relaciona con el currículum, lo que disminuye la relevancia institucional que podría tener. Junto con ello, existe un bajo monitoreo de las acciones realizadas y casi nula evaluación del PFC (PNUD, 2018). A su vez, existe poca disponibilidad de recursos y de tiempo para que los profesionales trabajen en torno a las acciones del Plan, según los resultados de la etapa cualitativa del informe realizado por el Programa de las Naciones Unidas para el Desarrollo (PNUD, 2018).

Considerando las dificultades encontradas hasta la fecha para el favorable funcionamiento del PFC, un gran desafío que se presenta es diseñarlo a través de una estrategia más participativa. Esto involucra tanto al proceso de elaboración, como una participación sistemática y no puntual en la implementación del Plan y en la evaluación de las acciones realizadas. Para ello es necesario incluir a todos los estamentos de la escuela: estudiantes, profesores, apoderados, directivos y asistentes.

Lo anterior se vuelve aún más relevante al comprender que la sociedad actual demanda un nuevo tipo de ciudadano comprometido con la cohesión social, la cooperación y la necesidad de fomentar la construcción de comunidades educativas democráticas (Cox \& Castillo, 2015). Con el fin de centrarse en el contexto particular de cada comunidad educativa, Haste (2017) propone un enfoque que entienda los motivos, las habilidades, los conceptos y las prácticas sociales desde el discurso y la experiencia de los estudiantes para elaborar programas de formación ciudadana más efectivos.

En definitiva, debido a la urgencia de promover una ciudadanía activa y las dificultades que tienen las propuestas políticas educativas emanadas desde el Ministerio para aplicarse en las escuelas, es que este tema es relevante de estudiar. A continuación, se describen las sugerencias que plantea el MINEDUC para elaborar el PFC de manera colectiva y que tienen como fin relevar el contexto de cada escuela. 


\section{RECOMENDACIONES MINISTERIALES PARA LA ELABORACIÓN DEL PLAN DE FORMACIÓN CIUDADANA}

Para lograr los objetivos del PFC, el Ministerio de Educación propone realizar una reflexión diagnóstica con la comunidad educativa, definir los desafíos y priorizar las acciones de formación ciudadana, con el fin de relevar sus particularidades territoriales. Este proceso tendría que involucrar, idealmente, la participación de todas y todos, para fijar metas y tareas con el fin de dar solución y respuesta a los desafíos que se planteen (Mineduc, 2016b).

Además, se propone que este Plan se articule con el Proyecto Educativo Institucional (PEI) y con el Plan de Mejora Educativa (PME), visualizando las prácticas pedagógicas que existen y que promueven el desarrollo democrático en escuelas y liceos. A su vez, se sugiere identificar qué acciones o actividades que se están implementando en el establecimiento corresponden al ámbito de la formación ciudadana y son posibles de vincular con los objetivos que establece la ley, antes de proponer nuevas acciones (Mineduc, 2016b).

De esta manera, la formulación del PFC se plantea idealmente como el resultado de un proceso de reflexión comunitaria donde participan directivos, estudiantes, familias, docentes y asistentes de la educación y que contempla algunas etapas definidas internamente (Mineduc, 2016b). Pese a la importancia que se le entrega a este diagnóstico reflexivo, el Ministerio de Educación sólo entrega como herramienta algunas preguntas que debe responder el equipo de gestión: “¿Qué prácticas del área de Gestión Pedagógica, Liderazgo, Convivencia y Recursos apoyan el desarrollo de temas vinculados a la formación ciudadana?” (Mineduc, 2016b, 43), las que tienen como fin identificar fortalezas y debilidades, realizando una evaluación amplia de las áreas y dimensiones propias del PME. En síntesis, se dan indicaciones generales para realizar un diagnóstico, pero no se orienta en profundidad a la comunidad sobre cómo elaborar el PFC de forma democrática.

Estos lineamientos generales entregan libertad a las escuelas para crear instancias y acciones para reflexionar sobre sus prácticas, pero a la vez no proponen nuevas posibilidades que logren incentivar la participación democrática en una institución tradicionalmente vertical y conservadora. Incluso, aunque se indica en las Orientaciones del MINEDUC la necesidad de construir un PFC de manera participativa, le entregan la responsabilidad de su formulación al sostenedor del establecimiento (Ley $N^{\circ}$ 20.911), por lo que él tiene el poder resolutivo sobre el proceso de diseño e implementación del PFC. Bajo este contexto es que es relevante proponer una metodología que colabore con una formulación del PFC basada en un proceso democrático y participativo, con el objetivo de superar las dificultades observadas en la creación, implementación y monitoreo. Con este fin, en el siguiente capítulo se propone la metodología de Diagnóstico Participativo, como una alternativa de elaboración comunitaria del PFC en las escuelas. 


\section{DIAGNÓSTICO PARTICIPATIVO}

El Diagnóstico Participativo (en adelante DP) es una estrategia de evaluación que se realiza desde las ciencias sociales y la educación popular. Su enfoque está basado en la participación de las comunidades para identificar sus problemas y plantear soluciones a través de la cooperación entre los actores y la construcción de una ciudadanía activa. De esta manera, la comunidad reconoce y valora sus recursos, desarrolla sus capacidades de planeación, diálogo y ejecución y durante este proceso aprende a colaborar y construir con otros, ampliando las prácticas y valores democráticos (Corporación RedEAmérica, 2014).

Este método permite obtener información útil, visualizando las áreas de mayor interés de la población (Ministerio de Salud [MINSAL], 2008). Asimismo, posibilita relevar la importancia del contexto, comprendiendo los problemas de una comunidad desde la misma, obteniendo el conocimiento necesario para planificar las soluciones a través de acciones colectivas.

Muñoz (1989) en el Manual sobre DP invita a la reflexión de las comunidades, proponiendo que las personas involucradas en los problemas deban comprobarlos, analizarlos e interpretarlos, con el fin de mirar críticamente la realidad. Esto lograría que las comunidades comprendan las causas de sus problemas y se motiven a realizar acciones transformadoras de su realidad (Muñoz, 1989).

Esta metodología está sustentada en la premisa de que las personas de la comunidad son los mejores conocedores de su propia realidad, lo que les daría mayor capacidad para priorizar y articular sus recursos disponibles (Muñoz, 1989). De esta manera, los participantes del DP deben identificar sus problemas, ordenándolos de acuerdo con el grado en que los afecten para encontrar soluciones adecuadas, interpretando la realidad que desean transformar. Según Espinoza y otros autores (2015) esto lograría un menor margen de error en la identificación de los problemas y una mayor eficacia en solucionarlos. Siguiendo esta idea, Niremberg (2006) añade que la participación de la comunidad fomentaría la viabilidad futura de los proyectos.

En síntesis, el DP permite conocer mejor las problemáticas de un territorio; establecer un proceso reflexivo de conocimiento sobre la propia realidad, sus problemas y sus causas; relevar el punto de vista de las personas pertenecientes a la comunidad y motivarlas hacia la búsqueda de soluciones viables.

Los DP incluyen los puntos de vista de todos los actores que viven la situación problemática, independiente del grado de poder que tengan, por lo que no se consideran los recursos económicos, materiales, de información, intelectuales, de influencia o de liderazgo de los participantes, ya que implica la integración de distintas miradas y diversas percepciones para la construcción conjunta del diagnóstico. Esto es denominado por Niremberg (2006) como trabajo intersubjetivo, ya que supone la confrontación de informaciones parciales mediante el trabajo grupal. 
Lo participativo de esta metodología radica en que los miembros de la organización participan de todas las etapas de la evaluación diagnóstica, no son sólo sujetos de los cuales se recolecta información. Son ellos los que toman las decisiones sobre qué, para qué y cómo diagnosticar a partir de la participación amplia y activa de la comunidad. Al controlar la información, tienen poder de decisión y su participación es decisiva en la formulación de las conclusiones del diagnóstico (Astorga \& Van Der Bijil, 1991).

Niremberg (2006) es enfática al describir el DP como un proceso permanente y abierto al enriquecimiento de revisiones posteriores a medida que se avanza en el desarrollo de la intervención. Diversos autores han definido distintas etapas del DP considerando el contexto propio del que se hacen cargo (Muñoz, 1989; Astorga \& Van Der Bijil, 1991; Niremberg, 2006; MINSAL, 2008; Subsecretaría General de Gobierno, 2010; Corporación RedEAmérica, 2014). Sin embargo, estas propuestas son coincidentes en los siguientes aspectos indicados en la Fig. 1:

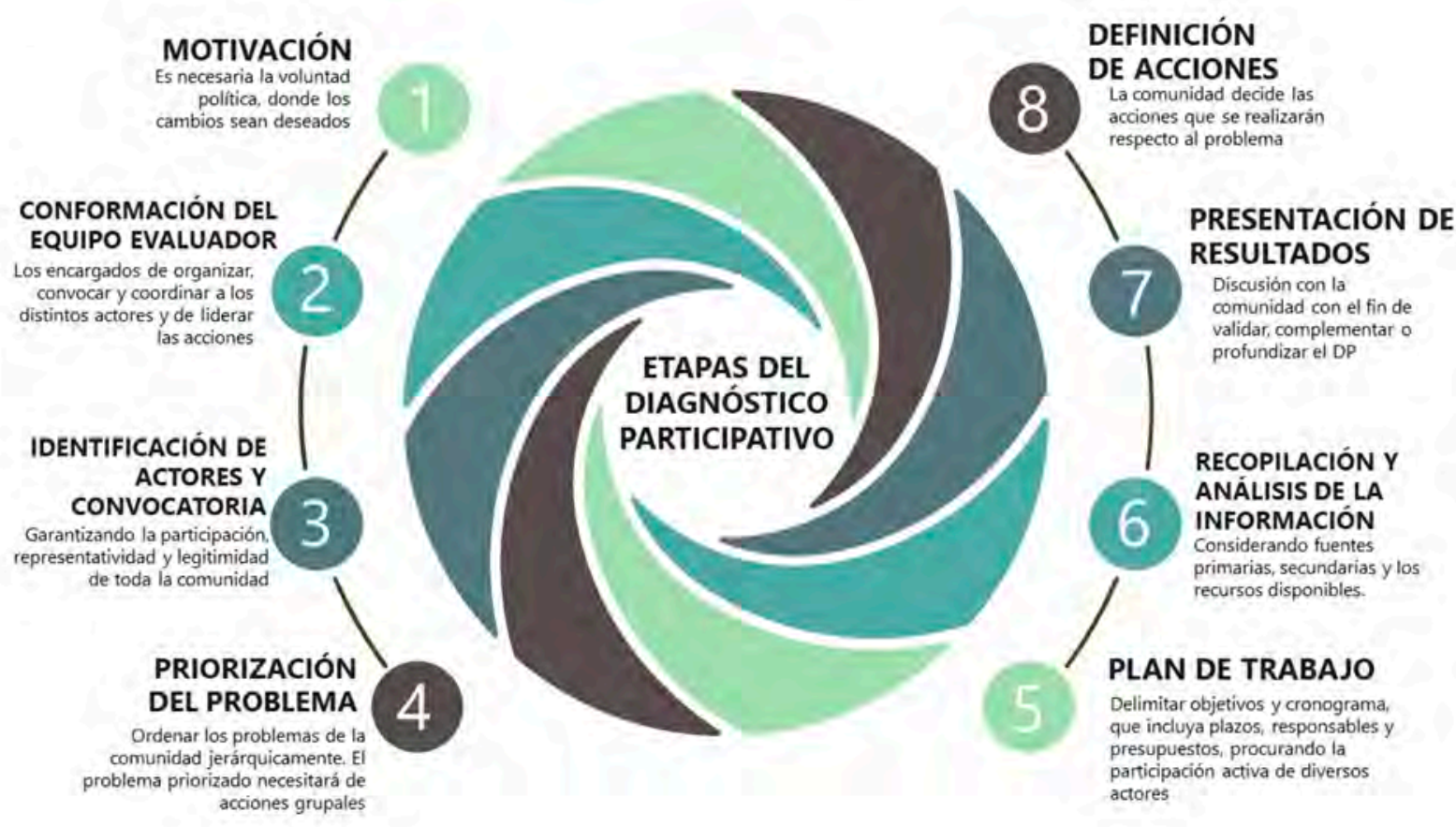

Fig. 1. Etapas del Diagnóstico Participativo.

Elaboración propia a partir de Astorga \& Van Der Bijil, 1991; Corporación RedEAmérica, 2014; MINSAL, 2008; Muñoz, 1989; Niremberg, 2006; Subsecretaría General de Gobierno, 2010.

\section{METODOLOGÍA}

El diseño del DP para la elaboración del PFC en las escuelas se plantea desde los principios de la Investigación Acción Participativa, en adelante IAP, que se basa en una investigación que incluye la participación protagónica de los sujetos con el fin de mejorar situaciones colectivas (Alberich, 2008). De esta manera la IAP se configura tanto 
como una metodología de investigación y como un proceso de intervención, en donde el trabajo se fundamenta en la participación de las comunidades y en la sistematización de sus saberes.

La IAP propone el análisis de la realidad desde el conocimiento y sensibilización de la población, con una metodología flexible de acuerdo al territorio que se interviene y de los objetivos que se persiguen, reconstruyéndose a partir de la praxis de los sujetos. En el ámbito pedagógico se define a la IAP como una investigación en donde las personas que la dirigen actúan como ciudadanos que pretenden influir en el proceso político a través de la recogida de información (Cook \& Reichardt, 2005).

Uno de los propósitos de la IAP es la transformación de la realidad a partir de la identificación y mejora de problemáticas sociales. Tiene como fin realizar un proceso en donde la comunidad involucrada trabaja desde la intersubjetividad y su contexto, tomando como premisa dentro del proceso de investigación el ejercicio y análisis colectivo de la información recolectada y sistematizada por el grupo, con el objetivo de generar acciones en busca de transformar la realidad social de las personas involucradas en la investigación (Guardiola, 2017). De esta manera, el rol del investigador se expresa como un científico social que tiene el propósito de disminuir la injusticia en la sociedad y que ayudará a los miembros de las comunidades a incrementar el poder que tienen ellos sobre aspectos relevantes de sus vidas (Folgueiras-Bertomeu \& Sabariego-Puig, 2018).

La presente investigación trabaja el DP desde la perspectiva de una investigación de naturaleza cualitativa, ya que se orienta hacia la búsqueda de experiencias, percepciones y sentimientos de una comunidad educativa tratando como foco principal el tema de la Formación Ciudadana en la escuela. El marco interpretativo desde donde se desarrolló la investigación es el social constructivista, considerando el marco teórico entregado por Krause (1995). Desde la ontología se asume que existen múltiples realidades construidas a través de nuestras experiencias de vida. De tal manera, durante la investigación la voz de los informantes fue fundamental, e incluso se consideraron las propias experiencias de vida de la investigadora, dando cuenta de su experiencia como profesora de la institución donde se realizó la investigación. Por ello, se consideró su propia percepción sobre la formación ciudadana impartida por el colegio, ya que desde la epistemología se apuesta a que la realidad es co-construida entre el investigador y los investigados y conformada por las experiencias individuales. Es por tanto una epistemología subjetivista (Krause, 1995).

La muestra estuvo compuesta por un establecimiento educacional de la comuna de El Bosque. Siguiendo la metodología del DP, los participantes fueron los integrantes del Equipo Evaluador, compuesto por docentes, estudiantes y un apoderado. Para la recolección de datos, se consideraron documentos institucionales (Proyecto Educativo Institucional, Plan de Formación Ciudadana y Plan de Convivencia) y entrevistas semiestructuradas grupales e individuales cuyo guión fue confeccionado en base a los resultados de la reunión con el Equipo Evaluador. 
Al analizar los datos, se utilizó una metodología inductiva de ideas emergentes obtenidas a través de entrevistas grupales e individuales semiestructuradas. Los instrumentos fueron transcritos y los datos fueron analizados por medio de una codificación mixta de códigos establecidos previamente por el Equipo Evaluador y códigos emergentes con la intención de expresar los datos y fenómenos a través de conceptos, ya sean palabras o secuencias breves de palabras (Gibbs, 2012). En el siguiente esquema estilo "nube de palabras" (Fig. 2) se pueden observar los códigos establecidos previamente y los códigos emergentes, en donde el tamaño de las palabras depende de la cantidad de veces utilizada en el proceso de codificación.

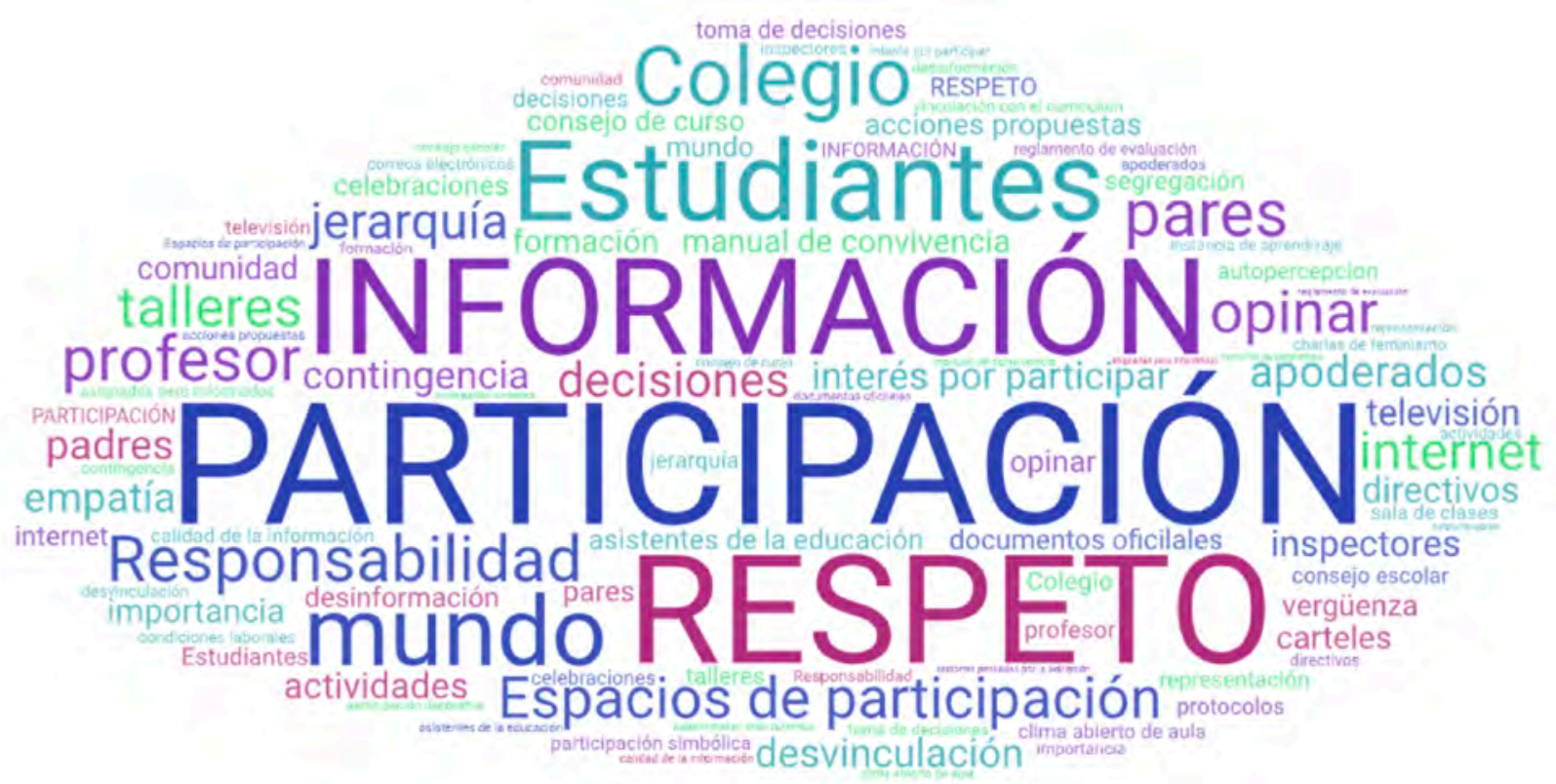

Fig. 2. Nube de palabras creada a partir de la codificación mixta realizada. Fuente: Elaboración propia realizada a través de la plataforma wordart.com.

La interpretación de los datos se realizó paralelamente a la recolección de éstos, para dar la posibilidad de recoger datos adicionales a los que estaban previstos. A su vez, se utilizó el software Dedoose como gestor de datos cualitativos.

Al finalizar el análisis de las entrevistas grupales e individuales y los documentos institucionales, se procedió a triangular la información con marcos teóricos relevantes (Gibbs, 2012). A través de este proceso de análisis de datos se buscó activamente alcanzar interpretaciones altamente informadas en donde las construcciones individuales fueron comparadas y contrastadas, con el fin de lograr un consenso sustancial de la información recolectada (Krause, 1995). El objetivo de la triangulación no significó buscar una interpretación única de la realidad, sino que revelar nuevas dimensiones de la realidad social de las personas (Gibbs, 2012). 
Implementación del DP

El DP se modeló según el contexto en el que sería implementado, siguiendo el orden lógico propuesto por los autores estudiados (Muñoz, 1989; Astorga \& Van Der Bijil, 1991; Niremberg, 2006; MINSAL, 2008; Subsecretaría General de Gobierno, 2010 Corporación RedEAmérica, 2014). De esta manera se enfatizó la importancia de la comunidad educativa para la realización de este proceso y se priorizaron algunas etapas por sobre otras para que pudiera ser realizado en un tiempo acotado, durante el segundo semestre del año 2018. Se consideraron como posibles participantes del DP a estudiantes, asistentes de la educación, docentes, directivos y apoderados, a los que se invitó de manera abierta y cuya participación fue voluntaria. Para lograr su realización, lo primero que se consiguió fue la Autorización Institucional de la directora y sostenedora del establecimiento. Los siguientes pasos que se realizaron se sintetizan en el siguiente esquema (Fig. 3):

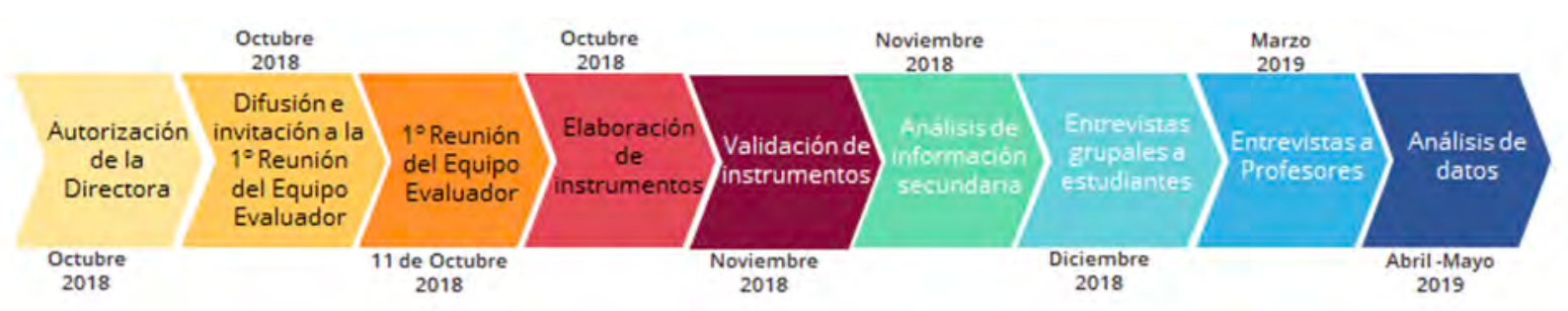

Fig. 3. Implementación del Diagnóstico Participativo en establecimiento educacional (2018-2019).

Fuente: Elaboración propia

Para incentivar la participación de distintos actores en el Diagnóstico Participativo, antes de la primera reunión del Equipo Evaluador se crearon afiches que fueron instalados en distintas partes de la escuela y se informó en la reunión de apoderados, el consejo de profesores, a la Encargada de Convivencia Escolar y al presidente del Centro de Estudiantes, con el objetivo de lograr una mayor convocatoria. Con estas acciones se buscaba difundir la importancia de la participación de diversos actores para la creación del Plan de Formación Ciudadana, con el fin de crear una escuela más democrática, participativa y transformadora. Se logró que en la primera reunión del Equipo Evaluador asistiera un representante del Centro de Estudiantes, un apoderado y cuatro profesores.

En dicha reunión, a partir de la herramienta del “Árbol de problemas”, se generó una discusión entre estos actores con respecto a las fortalezas y debilidades de la formación ciudadana en la escuela. Como resultado, el Equipo Evaluador levantó tres ejes relevantes para fortalecer los procesos de formación ciudadana en la escuela: Respeto, Información y Participación en la escuela. Para el Equipo Evaluador, la formación ciudadana está relacionada con las acciones que puede realizar la comunidad educativa para fomentar los espacios ciudadanos de los estudiantes, desde aprender a escuchar opiniones de manera respetuosa, informarse sobre el acontecer nacional y escolar y lograr una participación en la toma de decisiones. Estos tres ejes fueron considerados una buena síntesis de la discusión realizada con respecto a temáticas claves para fomentar la formación ciudadana considerando el contexto del establecimiento. 


\section{RESULTADOS}

En base a la información levantada desde el Equipo Evaluador se realizaron tres entrevistas grupales a estudiantes y tres entrevistas individuales a profesores, las cuales se analizaron a partir de tres ejes centrales: Respeto, Información y Participación, categorías que representan las prioridades establecidas para la elaboración del Plan de Formación Ciudadana en la escuela, las que son resumidas en la Fig. 4.

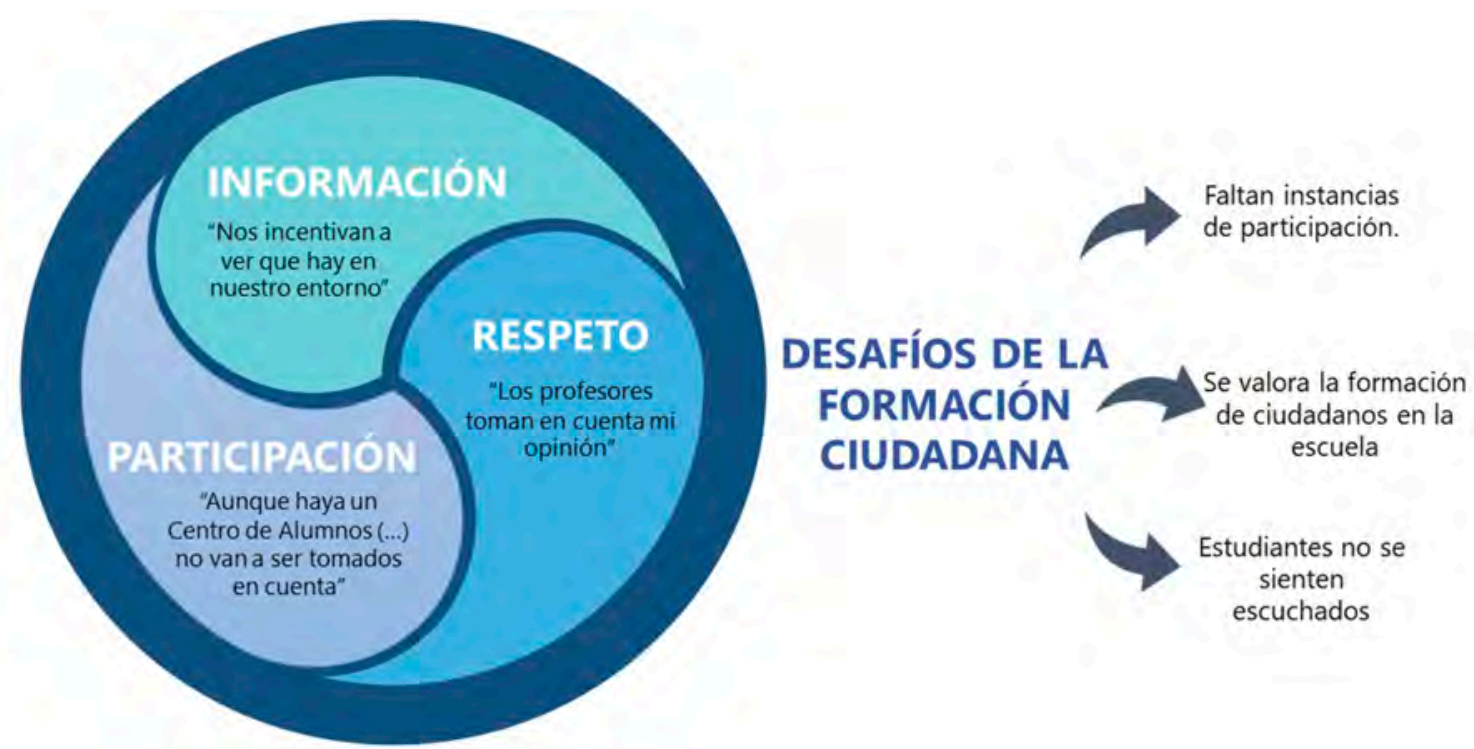

Fig. 4. Síntesis del trabajo realizado por el Equipo Evaluador en octubre del año 2018. Fuente: Elaboración propia.

\section{Respeto}

Los estudiantes consideran que en el colegio se vive generalmente en un ambiente de respeto entre los distintos actores de la comunidad escolar. Esto es reafirmado por los testimonios de los profesores entrevistados: "Creo que hay una relación de cariño profundo. Ni siquiera te diría como de respeto. Yo siento que el respeto es la consecuencia de la relación de amor que hay con los estudiantes" (E1, 2019).

En general los estudiantes manifiestan que la relación que tienen con sus profesores es de respeto mutuo, valoración, confianza y cariño sincero. Este respeto se expresa en el clima que se genera dentro del aula, por ejemplo, cuando los profesores les dan el espacio para opinar y los escuchan. Esta situación la expresan por igual estudiantes de tercero medio y de séptimo básico de las entrevistas grupales (EG3, 2018 y EG7, 2018). Una estudiante menciona:

Los profesores te toman en cuenta tu opinión o te escuchan, porque hay en otras partes, en otros colegios, que no lo hacen. Como que si tú quieres opinar, no, porque el 
profesor es el que manda[...] Uno se siente como que te están valorando y respetando. (EG7, 2018)

Además, se vislumbra un ambiente de confianza y respeto entre los estudiantes en la sala de clases, lo que les permite discutir libremente con sus compañeros: "Me siento en tanta confianza con ellos que fácilmente me puedo poner adelante y decir esto, esto y esto" (EG3, 2018).

\section{Información}

Los estudiantes mencionan que los profesores los incentivan a informarse sobre temas de actualidad y que en las clases de lenguaje, historia, filosofía, inglés, religión y matemáticas se habla de noticias o temas contingentes.

Los profesores declaran que ellos planifican actividades que tienen relación directa con el intercambio de ideas sobre el acontecer nacional, como debates, investigaciones, tesinas, reflexiones sobre lecturas o videos y que las relacionan con el currículum vigente (E1 y E2, 2019). Incluso, si aparece alguna mención en clases sobre algún tema contingente y no lo tenían planificado, no pueden dejar de lado la motivación que tienen los estudiantes por informarse o por opinar sobre un tema, y se dan el tiempo de conversar sobre sus intereses (E1 y E3, 2019). Un profesor menciona: "A medida que la contingencia nacional lo amerita, ellos demandan, tienen dudas, preguntan [...] necesitan como satisfacer esas dudas, esa necesidad de conocimiento [...] como que les encanta empoderarse en los temas" (E3, 2019).

Los estudiantes valoran positivamente el interés que tienen los profesores por generar estas instancias y promoverlas, tratando temas como el aborto, la legalización del consumo de marihuana, la eutanasia, las demandas feministas, la migración, la desigualdad social, etc. (EG1 y EG2, 2018). Además, consideran de suma importancia establecer estos espacios porque: "Nos incentiva a ver qué es lo que está pasando afuera de nuestro entorno, [...] uno tiene que interesarse por lo que están pasando las demás personas" (EG7, 2018). El rol del profesor lo relacionan con un vínculo con otras realidades y con reflexionar sobre los privilegios que tienen (EG7, 2018).

En general, los estudiantes no consideran que exista una intención de la escuela por fomentar que ellos busquen información por sí mismos sobre el acontecer nacional y relatan su experiencia anclada a esfuerzos individuales de algunos profesores que lo hacen en sus clases. Los profesores expresan el esfuerzo que hace el cuerpo docente por informar a los estudiantes sobre lo que sucede en su país. Sin embargo, como no es una decisión institucional incentivar a que los estudiantes se informen sobre hechos contingentes, significa que no todos los profesores trabajan ese tema por igual, ni que en todos los cursos se ha trabajado de igual manera (E3, 2019). 


\section{Participación}

Los profesores durante las entrevistas declaran que existen algunos espacios de participación para la comunidad educativa como el Día de la Familia, la Peña Folclórica, el Aniversario del colegio y el Día del Alumno, los que tienen un enfoque conmemorativo o festivo (E1, 2019).

Además de todos estos espacios, los estudiantes pueden participar en el Centro de Alumnos. Sin embargo, un profesor entrevistado lo considera como una oportunidad que no ha sido bien aprovechada por los jóvenes (E1, 2019). Los estudiantes, por otra parte, valoran que exista este espacio de representación que ayude a los estudiantes (EG7, 2018). Sin embargo, lo consideran insuficiente y para algunos entrevistados sólo tiene un valor decorativo, una especie de organismo que sólo existe para cumplir con la normativa legal de creación de un Centro de Estudiantes, pero que no es escuchado por las autoridades del colegio. Un estudiante de Tercero Medio declara: “Aunque haya un Centro de Alumnos y ponga una idea o planes, no van a ser tomados mucho en cuenta” (EG3, 2018).

Otro punto que merma la importancia que podría tener el Centro de Estudiantes es la poca información que tienen éstos sobre lo que realiza o los planes que tiene el Centro de Alumnos. Los estudiantes de Primero y Segundo Medio mencionan que el Centro de Estudiantes no les informa sobre lo que están haciendo y no les preguntan la opinión al resto de los estudiantes, por lo que expresan su molestia: "Supuestamente el Centro de Alumnos deberían ser nuestros representantes para tomar decisiones y preguntarnos a nosotros qué queremos hacer, pero no lo hacen” (EG1 y EG2, 2018). El Centro de Estudiantes está en conocimiento de estas falencias y durante el año 2018 pidió autorización para realizar una asamblea con todos los estudiantes, donde se pudiera informar sobre las propuestas que han presentado en las reuniones que buscan la modificación del Manual de Convivencia, pero la Dirección del establecimiento no los autorizó (EG3, 2018).

Los alumnos de Tercero Medio miran críticamente las posibilidades que tiene su organización como estudiantes de influenciar en la toma de decisiones del establecimiento. Lo que comparan con otros colegios, en donde ellos creen que sí tienen importancia los centros de estudiantes para la comunidad educativa, lo que relata un estudiante: "(En los liceos) emblemáticos el Centro de Alumnos tiene una posición súper importante. Esos alumnos tienen decisiones reales" (EG3, 2018). Consideran que la participación que tiene su Centro de Estudiantes es muy marginal, porque tampoco se los invita a participar en instancias donde se encuentren con la dirección del colegio. Un estudiante menciona: "Sigue siendo una participación entre comillas nula, por el hecho de que... es como muy rara vez se te invita a dialogar con la directiva" (EG3, 2018).

Aunque se los invite a conversar en algunos espacios, como el Consejo Escolar, donde participa el Presidente del Centro de Alumnos, la sensación que predomina entre los estudiantes es que no tienen participación en la toma de decisiones. Un alumno de 
Tercero Medio menciona que los estudiantes no participan "de ninguna forma" (EG3, 2018). Asimismo, un alumno de Séptimo Básico declara que los estudiantes "no tienen el poder necesario" para acceder a la toma de decisiones y otro compañero refuerza esta idea mencionando que solamente pueden dar ideas, pero que eso no influye en "los que mandan más" (EG7, 2018).

Estas opiniones negativas sobre el funcionamiento del Centro de Alumnos, sin embargo, no disminuyen las intenciones que tienen los estudiantes por participar de este espacio. Algunos estudiantes de Séptimo Básico mencionan que les gustaría participar para que tomen en cuenta sus opiniones y creen que este organismo puede lograr transformaciones en su espacio, "poder cambiar para bien este tipo de colegio" (EG7, 2018), lo que manifiesta el interés que tienen por participar.

Incluso este interés lo manifiestan estudiantes de Tercero Medio: "A mí sí me gustaría participar, porque siento que... algo se puede hacer, algo podemos dejarle a los demás" (EG3, 2018). Consideran que pueden hacer cosas para los futuros estudiantes, dejando a un lado la individualidad, pensando en los otros y en el bien común. Un estudiante menciona: "Encuentro bacán como ser el responsable del cambio. Como que sentís que hiciste algo por mejorar de lo que tanto te quejai" (EG3, 2018). En esta misma línea, la participación la vinculan con el sentido de pertenencia por su escuela, ya que buscan mejorar "nuestro colegio".

Los profesores vislumbran que los estudiantes tienen interés en opinar y participar en su escuela, sin embargo, según sus dichos, es la escuela la que no se hace cargo de entregar espacios de reflexión para ellos $(E 1,2019)$ ni de fomentar el trabajo del Centro de Alumnos:

Creo que de verdad, no hay ningún interés institucional de que funcione, como que no importa mucho y creo que se les traspasa a los alumnos. Yo creo que por eso el Centro de Alumnos como que parten con muchas ideas y terminan como chatos, (...) porque no se les da el espacio (E2, 2019).

A pesar de este contexto los estudiantes han propuesto diversas actividades que se podrían realizar en su escuela, por ejemplo, campeonatos de bandas, huerto escolar, sistema de rescate de perritos y adopciones, incluso un exalumno propuso trabajar en el CRA del colegio con el fin de mejorar la biblioteca. Una entrevistada manifiesta ante este hecho "pero siempre queda en eso, como qué bueno, qué bonito. Y después no se concreta nada" (E2, 2019).

Aunque estas ideas no se concretaron, sí han habido instancias que se han desarrollado con éxito. Ejemplo de ello es un ciclo de charlas en torno al género y el feminismo que se realizó a fines del año 2018 y que organizó una estudiante de Cuarto Medio. "Eso se concretó, pero también desde la buena intención, o sea, como sacrificando almuerzos, sacrificando tiempo de ella, de la Darling que debería haber estado en clases, por ejemplo. Pero así, eso 
tuvo éxito, o sea pudo hacerse" (E2, 2019). El espacio se concretó gracias al esfuerzo y la voluntad férrea de la estudiante para que se llevara a cabo el proyecto. Unió fuerzas con un compañero de curso, la profesora asesora del Centro de Estudiantes y un profesor practicante de Lenguaje. Los estudiantes durante las entrevistas también valoraron esta instancia de conversación que se realizó en su escuela y además mencionaron que a partir de aquélla se reactivó la "Comisión de Igualdad de Género".

Con respecto a los espacios de participación dentro de la sala de clases los estudiantes de Séptimo destacan el ambiente participativo que existe en ellas, donde no se les condena si se equivocan, sino que se valoran sus intervenciones "yo en la básica [...], preguntaban algo en lenguaje, en historia, en cualquier ramo, menos en ciencias naturales, no contestaba porque me daba miedo equivocarme, pero aquí no, porque aquí aprendí que es bueno equivocarse" (EG7, 2018). En definitiva, los estudiantes valoran un clima de aula abierto a la participación, a la expresión de ideas y lo consideran una oportunidad para el aprendizaje.

Sin embargo, en la asignatura de Consejo de Curso existen diversas opiniones. Algunos estudiantes valoran este espacio, porque les permite resolver los conflictos cotidianos que tienen en el curso $(E G 7,2018)$. Pero para otros es un espacio desaprovechado, donde no se hacen muchas cosas (EG1 y 2, EG3, 2018). Con respecto a esta situación, los profesores declaran que en realidad, durante el horario de Consejo de Curso ellos tienen que cumplir con planificaciones que les entregó Convivencia Escolar que tienen que ver con educación sexual, en consecuencia el horario está más ligado a un curso de "Orientación" que de "Consejo de Curso", por lo que manifiestan su molestia, frente a un espacio de organización desaprovechado: "Entonces cuando po', ¿en qué minuto ellos reflexionan respecto a su propia realidad? ¿Cuándo les dai ese espacio real? [...] No. No hay espacios de reflexión para los cabros, no existen" (E1, 2019). Los profesores entrevistados manifiestan la importancia que debería tener para la institución que los estudiantes tengan espacios de participación.

\section{La formación ciudadana en la escuela}

Las entrevistas que se realizaron durante el DP también dieron paso a reflexiones sobre los problemas y los desafíos de cómo enseñar la ciudadanía en la escuela. En primer lugar, los profesores destacaron la importancia que tiene enseñar sobre ciudadanía en la escuela (E1, E2, E3, 2019) y son críticos con respecto a las instancias de participación que tienen los estudiantes en la escuela, ya que no las consideran significativas para ellos (E2, 2019). Con respecto a este tema un profesor menciona al finalizar la entrevista: “(Este) es un lugar que tiene mucho potencial de participación, creo que se está como desaprovechando igual. Y como que con las preguntas (de la entrevista) fue más patente, que era muy evidente, la falta de instancias y espacios" (E2, 2019). 
Algunos estudiantes destacan que, aunque no existe una asignatura que se llame "formación ciudadana", es algo que se vive cotidianamente en la escuela, como declara un estudiante: "No se enseña directamente, a lo mejor po, la vivimos, más que otra cosa” (EG3, 2018).

De esta manera, podemos identificar que el DP se configuró como un espacio de reflexión sobre qué es la formación ciudadana y sobre cómo se les enseña a los estudiantes en la escuela. Se visualiza por parte de ellos como una instancia práctica o un vivir cotidiano.

Otro punto que queda claro, después de analizar las entrevistas, es que los estudiantes están interesados en crear espacios de participación en su escuela. Ellos declaran el entusiasmo que tienen por expresarse, por opinar y por sentirse escuchados:

Ojalá que propongan [...] espacios de participación de los alumnos [...] porque uno no se siente escuchado, y a mí me gustaría decir muchas cosas, cuando opinan del curso me gustaría dar mi opinión, porque me gusta opinar. Me gusta porque yo vivo, vivimos literalmente en este ambiente, tenemos que tener algún tipo de decisión, estamos todo el día aquí (EG3, 2018).

Finalmente, el DP se visualiza por los participantes como una oportunidad para dialogar y como un espacio que puede lograr mejores instancias de participación para lograr transformar la escuela.

El PFC de la escuela data del año 2017 y contiene trece acciones que debe realizar. Once de éstas se realizaban previamente en el colegio, antes de la formulación del PFC. Seis de las acciones son instancias de participación que promueve el Estado, por lo que son obligatorias para los establecimientos que reciben subvención estatal, como son: Consejos de Curso, Consejos Escolares, Consejos de Profesores, Elección de Centro de Padres, Elección de Directivas de Curso y Elecciones de Centros de Estudiantes.

La participación de los estudiantes está resumida a la elección de las directivas de curso y de Centros de Estudiantes, al igual que los apoderados que pueden elegir a su directiva del Centro de Padres y Apoderados. En particular la función del Consejo Escolar en el PFC es descrita como una instancia de carácter informativo y consultivo, nunca resolutivo, aunque la ley entregue esta posibilidad si es que el sostenedor lo desea.

Además, en cuanto a la formación de los estudiantes se intenta fomentar el diálogo entre ellos a través del Consejo de Curso y en la acción "expreso mi opinión” donde los estudiantes pueden expresar opiniones e intercambiar ideas en temas de interés público, según la descripción de la acción. Sin embargo, no queda claro en qué momento se les entregaría esta posibilidad a los estudiantes y cuál es su rango de acción.

En efecto, la formación ciudadana tiene como desafío lograr la participación futura de los estudiantes en un contexto en donde se vislumbra dificultosa la oportunidad de participación efectiva de aquéllos durante su escolaridad. 


\section{DISCUSIÓN}

\section{La participación en la escuela}

El tener acceso a mejores espacios de participación es una de las principales preocupaciones de los participantes. En la escuela donde se realizó la investigación existen instancias garantizadas por el MINEDUC para la participación de los distintos actores en la escuela, entre los que se consideran el Centro de Alumnos, el Centro de Padres y Apoderados y el Consejo Escolar, que están establecidos en la normativa vigente (Decreto 24, 2005; Decreto 524, 1990; Decreto 565, 1990).

Además, la institución cuenta con espacios de participación creados por las disposiciones curriculares del establecimiento, como los talleres que son de libre elección por los estudiantes y actividades conmemorativas como fiestas patrias, aniversario del colegio, semana de la literatura, de los pueblos originarios y las ciencias. Sin embargo, a pesar de todas estas oportunidades los estudiantes tienen la percepción de que su participación no es importante y que las acciones del Centro de Alumnos en la escuela son decorativas o de participación simple (Novella, 2008).

Esta situación puede explicarse desde la propuesta de Hart (1993) que entiende la participación desde la óptica de compartir las decisiones que afectan la vida propia y la vida de la comunidad en la que se vive. Siguiendo esta idea, aunque los estudiantes participan en diversas instancias que entrega el colegio, como no acceden a la toma de decisiones, la percepción que se genera es de un acceso restringido a participar en la escuela.

Considerando que la participación es la base de la convivencia democrática y un derecho fundamental de la ciudadanía, es necesario desarrollar en profundidad las instancias de participación en la escuela. Incluso, investigaciones pedagógicas declaran que la participación política futura está condicionada al hecho de que los estudiantes intervengan en la toma de decisiones de su escuela (Haste, 2017).

Es necesario enfatizar la importancia de lograr espacios de participación efectiva, ya que según Guichot (2013) la participación en la comunidad logra que una persona se "sienta ciudadana”. Para poder identificar los diferentes tipos de participación para niños y jóvenes, Hart (1993) elabora un esquema con distintos niveles, el que se conoce como "escalera de participación" y que establece 8 tipos distintos de participación, con distintos niveles de calidad.

Según el esquema que propone Hart (1993) en los tres primeros niveles no existe participación verdadera. Si consideramos el testimonio de nuestros entrevistados con respecto a la participación de los estudiantes en la escuela, 5 acciones que se realizan en el colegio: Peña Folclórica, la presentación del Séptimo Básico en la primera formación del año, las reuniones del Consejo Escolar y el Centro de Alumnos y las formaciones 
que se realizan los lunes en los actos cívicos se considerarían en este criterio. En estas instancias los niños y jóvenes de la escuela tienen una participación decorativa o simbólica. La participación decorativa (2) hace referencia a las ocasiones en donde los estudiantes son parte de alguna instancia de participación, pero no saben de qué se trata y ninguna posibilidad de participar en la organización. Siguiendo esta línea, en la participación simbólica (3) se les da la posibilidad a los niños de expresarse, pero en realidad no tienen incidencia sobre el tema.

En los niveles de participación real se encontrarían las demás instancias de participación que son nombradas durante las entrevistas, sin embargo, la mayoría están concentradas en los niveles más bajos de acceso a la toma de decisiones. En el nivel de participación asignada (4) es donde se concentran más actividades realizadas en la escuela. En esta etapa los estudiantes son informados y su participación es asignada según las decisiones de los adultos: talleres, la semana de la literatura, de los pueblos originarios, de ciencias y el día de la familia. En este nivel los estudiantes comprenden las intenciones del proyecto y ellos tienen un papel significativo en la realización de la actividad, pero no se pueden ofrecer como voluntarios para las actividades, ya que fueron asignados sus roles por los adultos encargados.

En el siguiente nivel de participación la población es informada y consultada (5), los proyectos son diseñados y dirigidos por los adultos e igualmente los estudiantes comprenden el proceso y sus opiniones se toman en cuenta. Ejemplo de ello es que las elecciones del Centro de Estudiantes son dirigidas por adultos, estableciendo plazos y condiciones, pero los estudiantes pueden participar voluntariamente e incluso la decisión de la mayoría de los ellos se respeta. La planificación del Aniversario del Colegio también es consultada a los estudiantes miembros del Centro de Estudiantes, sin embargo, las decisiones sobre qué es lo que se realizará son tomadas por la dirección del establecimiento.

En el nivel ideal de participación en donde las decisiones son iniciadas por los estudiantes y coordinadas con un adulto (8) se encuentra solamente una actividad que organizó una estudiante de Cuarto Medio. En esa oportunidad ella tuvo una idea que comunicó a sus compañeros y profesores, los cuales le ayudaron a organizar un ciclo de charlas sobre el tema de género y el feminismo y en donde el resto de los estudiantes participó voluntariamente durante la hora de almuerzo por algunas semanas. Esta instancia fue tan significativa que fue nombrada de manera muy positiva por los entrevistados.

La Fig. 5 indica los niveles de participación de los estudiantes en la escuela, basada en las acciones del PFC. Se clasificaron 13 acciones que se realizaron durante el año 2018 en la escuela y que fueron nombradas por los estudiantes durante las entrevistas grupales. Cabe enfatizar que la mayoría de las acciones se concentra entre el nivel 2 y 5 de participación, es decir, sólo una es de tipo proyectiva. Esta clasificación puede revisarse a continuación: 


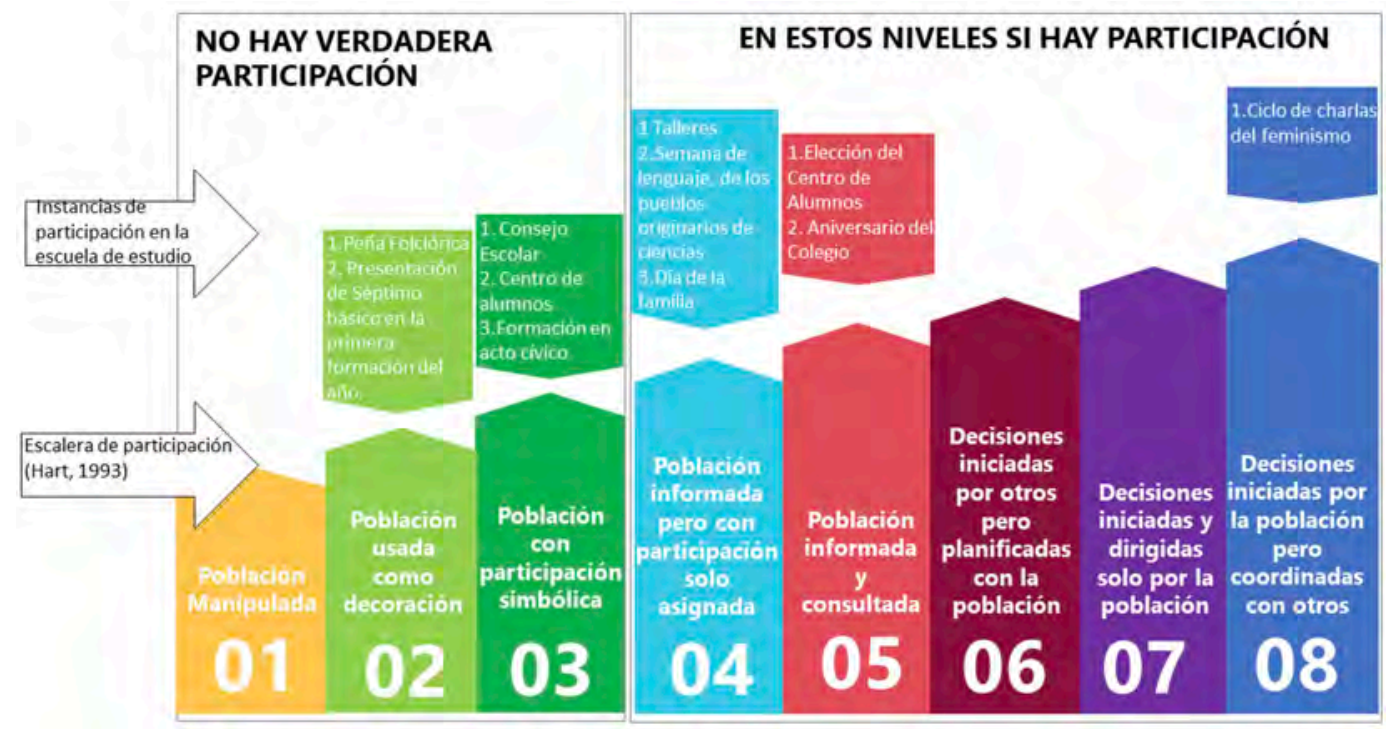

Fig. 5. Clasificación de los niveles de participación de los estudiantes en la escuela según la Escalera de Participación de Hart (1993).

Aunque quizás no sea la intención de la institución relegar a los estudiantes a un nivel de participación simple o solamente informado y consultado, es esa la percepción que tienen los estudiantes. Una alternativa disponible para mejorar esta percepción sería visibilizar las posibilidades que tienen los estudiantes en la toma de decisiones, transparentando e informando a éstos acerca de las funciones del Centro de Estudiantes, del Centro de Padres y el Consejo Escolar.

Si las condiciones de participación de los estudiantes se mantienen y no se les informa sobre el acceso que tienen a la toma de decisiones, terminarán pensando que la participación que poseen es ficticia, que es lo que sucede actualmente. En consecuencia, es imperativo que el PFC maximice la oportunidad de que los niños seleccionen su propia participación a su máximo nivel de habilidad, tal como sugiere Hart (1993).

Una posibilidad para fomentar espacios de participación y de formación de ciudadanos en la escuela es dar relevancia a la asignatura de Consejo de Curso que los estudiantes sienten que es desaprovechada. Es más, las bases curriculares que provee el Ministerio para esta asignatura no entregan objetivos claros, pero explicita que entre sus actividades es recomendable realizar prácticas básicas democráticas, por lo que podría ser una instancia que le entregue a los estudiantes la oportunidad de organizar debates sobre temas contingentes. El espacio de posibilidades que se le entrega al Consejo de Curso es muy amplio, desde el desarrollo de los objetivos de aprendizaje orientados al logro de la participación y el sentido de pertenencia, como también a la resolución de conflictos y forjar actitudes como el respeto y la valoración de la diversidad. Además, se considera como un espacio para fortalecer las relaciones interpersonales. Que exista este espacio de manera institucional entrega la posibilidad de tener un tiempo, aunque sea breve, para fomentar el interés de los estudiantes en temas de actualidad, realizar debates, discutir temas controversiales y planificar acciones de interés para los estudiantes. 
Asimismo, una propuesta que dio el Centro de Estudiantes para fomentar la participación durante el año 2018 fue la posibilidad de realizar una asamblea general de estudiantes a la que no se le entregó autorización de parte de dirección. Sin embargo, es una instancia legal según la normativa vigente (Decreto 524, 1990), en donde todos los estudiantes de Segundo Ciclo Básico y Educación Media están autorizados para organizar y asistir a la Asamblea General con el fin de convocar a la elección de directiva del Centro de Alumnos, elegir la Junta Electoral, aprobar el reglamento interno del Centro de Estudiantes o pronunciarse sobre materias específicas que estén declaradas en el Reglamento Interno del Centro de Alumnos; incluso, aquélla debe reunirse en sesión ordinaria a lo menos una vez al año para pronunciarse sobre la cuenta de gestión anual de la directiva del Centro de Alumnos y convocar a la elección. De esta manera se pueden promover espacios, que son alentados legalmente y que fomentarían la organización estudiantil.

\section{La participación en la sala de clases}

Uno de los resultados más relevantes de abordar es la importancia que se le entrega al clima abierto de discusión en clases por parte de los estudiantes. Éstos relatan la importancia que tiene poder expresar sus ideas sin temor a equivocarse, poder opinar sin que se burlen sus compañeros y poder discutir temáticas que tengan diversas opiniones. Este ambiente coincide con lo que Bonhomme y colaboradores (2015) describen como un clima abierto y respetuoso que incentiva el proceso de aprendizaje de competencias ciudadanas. Los resultados de ICCS (2016) concuerdan en este punto, considerándolo como un factor que incide positivamente en el conocimiento y la educación ciudadana.

Otros estudios como el de Alivernini y Manganelli (2011) han comprobado estos hallazgos identificando que expresar las opiniones y discutir sobre temáticas que tienen diversas opiniones es un factor que incide positivamente en la formación de ciudadanos. Los profesores reconocen este ambiente que se genera en la sala de clases, sin embargo, no es tan relevante dentro de sus declaraciones como sí lo es para los estudiantes, dando cuenta de una práctica que existe en la escuela, que fomenta la ciudadanía y que los profesores realizan sin desarrollarla de manera intencionada para cumplir con este objetivo. En otras palabras, desconocen la importancia que tiene esta práctica para los estudiantes y para su formación como ciudadanos, aunque la realizan cotidianamente.

\section{El Diagnóstico Participativo}

El Diagnóstico Participativo tiene un enorme potencial para alentar los procesos de participación en las escuelas. En la intervención que se realizó, los distintos actores valoraron positivamente el espacio del DP como un lugar seguro donde reflexionar y comunicar sus ideas. Incluso, los estudiantes enfatizaron el entusiasmo que tienen por opinar sobre sus 
vivencias en el espacio escolar, la importancia que tiene para ellos formar parte de las decisiones que se toman en la escuela y sus deseos de participar en espacios tradicionales, como el Centro de Estudiantes, y a la vez crear nuevos y mejores espacios de participación. A los estudiantes les gustaría decir muchas cosas y el Diagnóstico Participativo significó crear un espacio de diálogo y participación significativo para ellos, lo que queda reflejado en las entrevistas grupales realizadas, que estuvieron marcadas por reflexiones sobre sus vivencias en el aula y sus propuestas para mejorar los espacios de información y participación que existen en la escuela donde se realizó la intervención.

Esto refuerza la importancia de alentar un proceso participativo de elaboración del PFC, ya que un diseño realizado comunitariamente animaría un trabajo en conjunto para lograr las acciones del Plan. Los participantes de este estudio demostraron su interés por lograr un PFC de manera comunitaria, escuchando las voces de los distintos actores. Considerando las indicaciones que entrega el Ministerio de Educación con respecto a su elaboración participativa, el DP se puede considerar como una herramienta para relevar las concepciones, pensamientos e inquietudes de la comunidad educativa de manera participativa.

$\mathrm{Al}$ respecto, quienes participaron de la IAP pudieron reflexionar en torno a los factores que inciden en la formación de ciudadanos en la escuela. De esta manera, los participantes reconocieron los aspectos positivos de su comunidad escolar, los desafíos que tiene la educación para la ciudadanía en su escuela y fueron capaces de planear y proponer instrumentos de recolección de datos.

Esta estrategia de evaluación diagnóstica fue capaz de demostrar el conocimiento que tiene la comunidad sobre los temas que viven cotidianamente en la escuela. Así pues, en el caso particular de estudio, los participantes demostraron comprender la formación ciudadana desde las esferas de las actitudes, el conocimiento y las habilidades, lo que se relaciona con la propuesta que el MINEDUC ha llevado a cabo en los últimos años. Además, destacaron la importancia que tiene la enseñanza para la ciudadanía en las escuelas, siendo considerada un tema de relevancia para la institucionalidad política de nuestro país.

Además, el DP relevó el conocimiento que ya poseía la comunidad educativa generando directrices para establecer proyectos que le den sentido a los participantes y que no sólo signifique cumplir con obligaciones ministeriales, cuestión que es una dificultad en la elaboración de los PFC según el PNUD (2018). Esta metodología, a la vez, enfatiza la importancia que tiene el contexto particular de cada escuela para lograr la ejecución de las políticas públicas.

Dar el espacio para que los distintos miembros de la comunidad escolar participen es una de las aristas de lo que significa una pedagogía con orientación democrática, por lo que el DP podría significar una buena estrategia para establecer espacios democráticos en la escuela. Finalmente, es necesario relevar la importancia que tienen las instituciones educativas en la formación de ciudadanos ya que son la primera comunidad formal en la que conviven los estudiantes, por ello la relevancia de establecer canales de participación para 
los niños y jóvenes en sus escuelas. De esta manera generar instancias donde estudiantes, profesores y apoderados de la comunidad escolar puedan tratar problemas o iniciativas, expresando ideas de cómo mejorar la escuela, es un modelo necesario de implementar en las instituciones educativas, para poder fomentar realmente la participación. Incluso, la metodología del DP puede implementarse como una acción del PFC, el que cumpliría con algunos objetivos que propone la Ley $\mathrm{N}^{\circ}$ 20.911(2016).

\section{CONCLUSIONES}

La presente investigación identificó los espacios de participación que existen en la escuela, propuso un espacio de participación comunitaria entre distintos estamentos y utilizó el DP como una herramienta de reflexión en torno a los problemas y desafíos de la comunidad educativa. Esto último es de vital importancia, ya que se demostró que se realizan acciones relacionadas con la formación de ciudadanos en la escuela que, sin embargo, no se llevan a cabo con esa intención. De esta manera, el DP abre la posibilidad de generar conciencia sobre lo que ya se está realizando en la escuela con la finalidad de formar ciudadanos activos y de promover acciones intencionadas con ese objetivo. Es decir, el DP no es solamente una herramienta para relevar las problemáticas de la comunidad, sino que también abre paso a una instancia reflexiva para comprender los elementos que hay que mantener y dar importancia en la escuela para fomentar una ciudadanía crítica.

Una elaboración comunitaria del PFC que integre a todos los estamentos de la escuela $y$ en donde las personas puedan postularse de manera voluntaria para ejecutar acciones del Plan, implica que no sólo el Encargado del PFC estaría a cargo de este proyecto, sino que su implementación pasaría a ser responsabilidad de la comunidad, los que pueden convertirse también en fiscalizadores que aseguren que se cumplan las acciones del PFC, generando un compromiso comunitario durante la ejecución de este proyecto. Todo lo anterior convierte al DP en una oportunidad de democratización en la escuela.

Algunas de las dificultades que presenta esta metodología es que se necesita tiempo por parte del Encargado del PFC para organizar y coordinar el funcionamiento del Equipo Evaluador y para supervisar las distintas etapas de recolección y análisis de datos. Este tiempo no está siendo entregado a los Encargados del PFC según el Informe del PNUD (2018). De esta manera, sin un Encargado que pueda disponer de tiempo para la realización del DP, se podría generar una instancia de participación frustrada para los participantes.

A pesar de las dificultades que se pueden presentar, los espacios de participación que entrega el DP podrían influir positivamente en los niños y jóvenes al considerarlos como un actor relevante a la hora de tomar decisiones. Incluso, esta metodología podría utilizarse en otros ámbitos de la vida escolar y no sólo reducirse como un espacio de creación del Plan de Formación Ciudadana. En tiempos donde la sociedad civil en Chile demanda más espacios de participación política, a través de fuertes protestas y manifestaciones desde octubre del año 
2019, es imprescindible crear espacios como el DP en la escuela, en donde los estudiantes aprendan a ser ciudadanos activos que puedan identificar problemas comunes y buscar soluciones en pos del bien común.

\section{REFERENCIAS}

Agencia de Calidad de la Educación (2017). ICCS 2016. Estudio Internacional de Educación Cívica y Formación Ciudadana. Presentación Nacional de Resultados. Recuperado de: http://archivos.agenciaeducacion.cl/PRESENTACION_EDUCACION_CIVICA.pdf [Revisado 26-02-2019].

Agencia de Calidad de la Educación (2018). Primer estudio nacional de formación ciudadana. Recuperado de: http://archivos.agenciaeducacion.cl/Presentacion_resultados_ Estudio_Nacional_Formacion_Ciudadana.pdf [Revisado 21-07-2020].

Alberich, T. (2008). IAP, mapas y redes sociales: desde la investigación a la intervención social. Postularía, 8(1), 131-151.

Alivernini, F., \& Manganelli, S. (2011). Is there a relationship between openness in classroom discussion and students' knowledge in civic and citizenship education? Procedia Social and Behavioral Sciences 15, 3441-3445.

Astorga, A., \& Van Der Bijil, B. (1991). Manual de Diagnóstico Participativo (2 Ed.). Buenos Aires, Argentina: Cedepo Humanitas.

Bonhomme, M., Cox, C., Tham, M. \&Lira , R. (2015) La educación ciudadana escolar de Chile 'en acto': prácticas docentes y expectativas de participación política de estudiantes. En C. Cox \& J. Castillo (Eds.), Aprendizaje de ciudadanía. Contextos, experiencias y resultados. (pp.373-425). Santiago, Chile: Ediciones Universidad Católica.

Cabrera, F., Donoso, T., Folgueiras, P., \& Luna, E. (2009). Participación ciudadana: un reto para educación para la ciudadanía. La Salle, Revista de la Educación, Ciencia y Cultura, 14, 63-84.

Cook, T., \& Reichardt, C. (2005). Métodos cualitativos y cuantitativos en la investigación evaluativa, (5ta Ed.). Madrid: Editorial Morata.

Corporación RedEAmérica (2014). Guía de diagnósticos participativos y desarrollo de base. Bogotá, Colombia: Corporación RedEAmérica.

Cox, C., \& Castillo, J. (Eds.) (2015). Aprendizaje de la ciudadanía. Contextos, experiencias, resultados. Santiago, Chile: Ediciones Universidad Católica.

Crescimbeni, C. (2015). Educación y ciudadanía en el siglo XXI. Revista SAAP Universidad de Buenos Aires, 9(2), 267-291.

Decreto 24 (2005). Reglamenta los Consejos Escolares. Recuperado de http://bcn.cl/1vglx [Revisado 27-08-2019] Decreto 524 (1990). Aprueba el Reglamento General de organización y funcionamiento de los Centros de Alumnos de los establecimientos educacionales segundo ciclo de enseñanza Básica y enseñanza Media, reconocidos oficialmente por el Ministerio de 
Educación. Recuperado de http://bcn.cl/1v0e7 [Revisado 27-08-2019].

Decreto 565 (1990). Aprueba el Reglamento General de Centros de Padres y Apoderados para los establecimientos educacionales reconocidos oficialmente por el Ministerio de Educación. Recuperado de http://bcn.cl/1v0e7 [Revisado 27-08-2019].

Espinoza, A., Espinoza , C., \& Fuentes, A. (2015). Retornando a Chaitén: diagnóstico participativo de una comunidad educativa desplazada por un desastre socionatural. Magallania, 43(3), 65-76. https://dx.doi.org/10.4067/S0718-22442015000300006

Folgueiras, P. (2009). Ciudadanas del mundo: participación activa de mujeres en sociedades multiculturales. Madrid: Síntesis.

Folgueiras-Bertomeu, P., \& Sabariego-Puig, M. (2018). Investigación-acción participativa. El diseño de un diagnóstico participativo. REIRE Revista d'Innovació i Recerca en Educación, 11(1), 16-25. http://doi.org/10.1344/reire2018.11.119047 [Revisado 07-07-2019].

Garcés, M. (2020). Estallido social y una nueva Constitución para Chile. Santiago, Chile: Lom Ediciones.

Gibbs, G. (2012). El análisis de datos cualitativos en Investigación Cualitativa. Madrid, España: Ediciones Morata.

González, S. (2007). La noción de ciudadanía en jóvenes estudiantes secundarios y universitarios: un análisis de estudios comparados de la nueva ciudadanía. En A. Zambrano, G. Rozas, I. Magaña, D. Asún \& R. Pérez-Luco (Eds.), Psicología comunitaria en Chile: evolución, perspectivas y proyecciones (pp. 105-118). Santiago: RIL Editores.

Guardiola, A. (2017). Convergencias de la investigación acción participativa y el pensamiento complejo. Investigación \& Desarrollo, 25(1), 192-223.

Guichot, V. (2013). Participación, Ciudadanía Activa y Educación. Teoría de la Educación, 25(2), 25-47. Salamanca: Ediciones Universidad de Salamanca.

Hart, R. (1993). La participación de los niños. De la participación simbólica a la participación auténtica. Ensayos Innocenti $\mathrm{N}^{\circ}$ 4. Oficina Regional para América Latina y el Caribe: Unicef.

Haste, H. (2017). Nueva ciudadanía y educación. Identidad, cultura y participación. Buenos Aires, Argentina: Paidós.

Jara, C., Sánchez M., \& Cox, C. (2019). Liderazgo educativo y formación ciudadana: visión y prácticas de los actores. Revista Calidad en la Educación, 51, 350-381. https://doi. org/10.31619/caledu.n51.687

Krause, M. (1995). La investigación cualitativa: un campo de posibilidades y desafíos. Revista Temas de Educación 7, 19-39.

Ley 20.911 (2016). Crea el Plan de Formación Ciudadana para los establecimientos educacionales reconocidos por el Estado. Diario Oficial de la República de Chile, Santiago.

Martínez, M.L., Silva, C., Morandé, M., \& Canales, L., (2010). Los jóvenes ciudadanos: reflexiones para una política de formación ciudadana juvenil. Última Década CIDPA Valparaíso, 32, 105-118. 
Ministerio de Educación (MINEDUC) (2016a). Orientaciones curriculares para el desarrollo del Plan de Formación Ciudadana. Santiago, Chile: Ministerio de Educación.

Ministerio de Educación (MINEDUC) (2016b). Orientaciones para la elaboración del Plan de Formación Ciudadana. Santiago, Chile: Ministerio de Educación.

Ministerio de Educación (MINEDUC) (2017). Orientaciones para la participación de las comunidades educativas en el marco del Plan de Formación Ciudadana. Santiago, Chile: Ministerio de Educación.

Ministerio de Salud (MINSAL) (2008). Guía de Diagnóstico Participativo. Documento en consulta. Santiago, Chile: Ministerio de Salud.

Miranda, V. (2011). Competencias ciudadanas en estudiantes secundarios. Revista de Psicología Universidad Viña del Mar, 1(1), 34-51.

Muñoz, M. (1989). El Diagnóstico Participativo. Santiago, Chile: Ediciones Paesmi.

Niremberg, O. (2006). El diagnóstico participativo local en intervenciones sociales. Cuaderno N44: Ceadel Centro de Apoyo al Desarrollo Local. Recuperado de: http://proinapsa. uis.edu.co/redcups/Biblioteca/Modelo\%20Participativo/ElDiagnostico-44.pdf [Revisado 0807-2019].

Novella, A. (2008). Formas de participación infantil: la concreción de un derecho. Educación Social, 38, 77-93.

Programa de las Naciones Unidas para el Desarrollo (PNUD), (2017). Diagnóstico sobre la participación electoral en Chile. Proyecto Fomentando la Participación Electoral en Chile. Santiago, Chile: Programa de las Naciones Unidas para el Desarrollo.

Programa de las Naciones Unidas para el Desarrollo (PNUD), (2018). Estudio sobre la puesta en marcha del Plan de Formación Ciudadana. Santiago, Chile: Programa de las Naciones Unidas para el Desarrollo.

Reyes, L., Campos, J., Osandón, L., \& Muñoz, C. (2013). El profesorado y su rol en la formación de los nuevos ciudadanos: desfases entre las comprensiones, las actuaciones y las expectativas. Estudios Pedagógicos, XXI(1), 217-237.

Servel (s.f). Estadística de participación por rango de edad y sexo. Elecciones 2017. Recuperado de: https://www.servel.cl/estadistica-de-participacion-por-rango-de-edad-ysexo-elecciones-2017/ [Revisado 16-08-2020].

Subsecretaría General de Gobierno (2010). Elaboración de Diagnósticos Participativos. Serie: Participación ciudadana para una mejor democracia. Santiago, Chile: Subsecretaría General de Gobierno.

Zúñiga, C., Ojeda, P., Neira, P., Cortés, T., \& Morel, M. (2020). Entre la imposición y la necesidad: implementación del Plan de Formación Ciudadana en escuelas chilenas. Revista alidad en la Educación, 52, 135-169. https://doi.org/10.31619/caledu.n52.767 